\title{
Cytoreductive stereotactic body radiotherapy (SBRT) and combination SBRT with immune checkpoint inhibitors (ICIs) in metastatic renal cell carcinoma
}

Jonathan Peng; Aly-Khan Lalani; Anand Swaminath

Juravinski Cancer Centre, McMaster University, Hamilton, ON, Canada

Cite as: Peng J, Lalani A-K, Swaminath A. Cytoreductive stereotactic body radiotherapy (SBRT) and combination SBRT with immune checkpoint inhibitors (ICIs) in metastatic renal cell carcinoma. Can Urol Assoc J 2021 January 4; Epub ahead of print. http://dx.doi.org/10.5489/cuaj.6963

Published online January 4, 2021

$* * *$

\section{Abstract}

Introduction: Preclinical evidence demonstrates the immunogenic potential of stereotactic body radiotherapy (SBRT). There is growing interest in investigating this interplay with the immune system in metastatic renal cell carcinoma (mRCC). Cytoreduction with SBRT and combination therapy with SBRT and checkpoint inhibitor immuno-oncology agents (IO) are two potential therapeutic strategies in $\mathrm{mRCC}$. In this review, we summarize the current clinical evidence for the use of cytoreductive SBRT to primary kidney and combination SBRT with IO.

Methods: A literature review for articles and abstracts published between January 2000 and March 2020 was conducted through the PubMed, the American Society of Clinical Oncology (ASCO), and the American Society of Radiation Oncology (ASTRO) database. Evaluation of studies followed the Preferred Reporting Items for Systematic Reviews and Meta Analyses (PRISMA) criteria.

Results: A total of three articles for cytoreductive SBRT and one article and three abstracts for combination SBRT and IO in mRCC met inclusion criteria for this review. Evidence for SBRT to primary kidney is limited by small series and pilot studies. Outcomes vary widely due to small patient numbers and study heterogeneity. Local control ranges from 85-100\% and one- and twoyear overall survival ranges from $38-71 \%$ and 19 é $53 \%$, respectively. Combination SBRT and IO are tolerable for patients with early data, suggesting grade 3-4 adverse event rates of $0-24 \%$. Long-term survival data is not yet available.

Conclusions: Cytoreductive SBRT and combination SBRT with IO therapy represent promising treatment strategies in $\mathrm{mRCC}$. The evidence for clinical benefit is currently limited and requires further study with well-designed, randomized, controlled trials. 


\section{Introduction}

Systemic therapy for metastatic renal cell carcinoma (mRCC) has advanced significantly in recent years. Initially, cytokine agents were the only options available for mRCC as it's generally resistant to traditional chemotherapy. Response rates to cytokine therapy was approximately $12 \%$ and had only a small improvement in median overall survival of 3.8 months (1) at the expense of significant toxicities $(2,3)$. Eventually targeted monotherapy with tyrosine kinase inhibitors (TKIs) showed both improved survival outcomes and tolerability compared to cytokine therapy $(4,5)$ and subsequently became first line for mRCC.

More recently, targeted agents were replaced as first line treatment by dual checkpoint inhibitor immuno-oncology agents (IO) (6-9). The role of cytoreductive nephrectomy $(\mathrm{CN})$ in mRCC, previously established in the cytokine era, has been revisited in the targeted therapy era where there may be upfront utility in appropriately selected patients (10-13). Historically, radiation therapy has played a limited role in the management of RCC as it is traditionally thought to be a radioresistant tumor.

The use of ablative doses with stereotactic body radiotherapy (SBRT) however has demonstrated favourable results in localized RCC (14) and to sites of metastases in mRCC (15). In addition, there is ample preclinical evidence that demonstrates the ability for SBRT to promote anti-tumor immune response in the tumor microenvironment $(16,17)$ and to work synergistically with IO to amplify the immune response (18-20). Thus, the use of cytoreductive SBRT to primary kidney (as an alternative to $\mathrm{CN}$ ) and combination SBRT with IO in mRCC are potential therapeutic strategies that could take advantage of this interplay with the immune system. We performed this review to summarize the current clinical evidence evaluating the role of SBRT to primary kidney in mRCC as well as the use of IO and SBRT for mRCC.

\section{Methods}

A literature review was conducted for full length research articles and abstracts published between Jan 2000- March 2020 using the Pubmed, American Society of Clinical Oncology (ASCO) and American Society for Radiation Oncology (ASTRO) databases. A broad search strategy with "text word" method was used. Details regarding search terms are available in eTable 1 in the online Supplement. Evaluation of studies followed the Preferred Reporting Items for Systematic Reviews and Meta Analyses (PRISMA) criteria. SBRT, according to ASTRO, was defined as high dose external beam radiation delivered precisely to an extracranial target in one or few fractions. It is characterized by patient immobilization, sparing of normal tissues from high dose radiation with steep dose gradients, sub-centimeter accuracy and accounting for organ motion.

For the first part of this review, studies were eligible for inclusion if SBRT was delivered to the primary kidney tumor in mRCC. Studies that combined the results of SBRT to primary and SBRT to metastatic sites in $\mathrm{mRCC}$ were excluded. For the second half of this review, we 
included articles where SBRT and IO were used together in mRCC. Studies that included ablative radiation to brain metastases alone, non-IO immunotherapy or multiple histologies where renal cell was $<10 \%$ of the patients were excluded. We limited our search to studies published in the English language. Case reports, reviews, editorials, and commentaries were excluded.

\section{Results}

After a comprehensive search of the Pubmed, ASTRO and ASCO databases, 3 full length articles were included in our review of SBRT to primary kidney in $\mathrm{mRCC}$ and 1 article and 3 abstracts were included in our review of combination SBRT and IO therapy for mRCC. A glossary index of terms in eTable 2 is included in the online supplement for radiation specific details. The CONSORT diagram for the literature search is demonstrated in Figure 1 (SBRT to primary) and Figure 2 (combination SBRT and IO). A summary of the study details is depicted in Table 1 (SBRT to primary) and Table 2 (combination SBRT and IO).

\section{SBRT to primary in $\mathrm{mRCC}$}

Treatment technique, parameters, and toxicity

Singh et al (21) examined the use of SBRT with a single dose of 15 Gy followed by CN 4 weeks later in a prospective series. SBRT was delivered using volumetric arc therapy (VMAT). The median planning target volume (PTV) was $441 \mathrm{~cm}^{3}$. CN was feasible with no intra-op or immediate post-surgical complications. The rate of grade 2 and 3 toxicities was $25 \%$ and $6 \%$ respectively, however this toxicity rate is reported post-surgery and not specific to SBRT.

Correa et al published both a prospective (22) $(\mathrm{N}=12)$ and retrospective $(23)(\mathrm{N}=11)$ series examining the role of SBRT for patients not candidates for $\mathrm{CN}$. The prospective series utilized a dose escalation scheme and the maximum tolerated dose was 35 Gy. Treatment was delivered using either VMAT or TomoTherapy. The tumor and entire ipsilateral kidney were included in the treatment volume to mimic CN. The median PTV was $763 \mathrm{~cm}^{3}$ with $\geq 95 \%$ of the volume receiving $95 \%$ of the dose. The majority of patients $(75 \%)$ experienced GI related toxicity. Grade 3 toxicities were experienced by $25 \%$ of patients. The retrospective series identified patients treated with doses ranging from 25-40 Gy, with 7 patients being treated to the tumor alone and 4 being treated to the whole kidney. The techniques used were VMAT, TomoTherapy or intensity modulated radiation therapy (IMRT). The median PTV was $819 \mathrm{~cm}^{3}$ with $\geq 95 \%$ volume receiving $95 \%$ of the dose. SBRT was well tolerated as grade 2 and 3 toxicity was reported in 1 patient $(9.1 \%)$ and grade 1 toxicity was reported in 5 patients $(45.5 \%)$. Creatinine clearance $(\mathrm{CrCl})$ did not differ pre and post SBRT. 


\section{Local control and survival}

Local control and survival outcomes vary widely between studies. The 1-year overall survival (OS) ranged from 38-71\% and 2-year OS ranged from 19-53\%. Median survival and local control rate is only reported in the Correa et al prospective and retrospective series. Median survival was 6.7 and 20.4 months and local control was $100 \%$ and $85 \%$ respectively. All three studies are representative of mostly biopsy proven clear cell histology.

Systemic therapy use

All three studies report use of systemic therapy either pre or post SBRT with no concurrent use. In the prospective Correa et al series, 2 patients received mTOR inhibitors (Temsirolimus or Everolimus) and 5 received a TKI (Pazopanib or Sunitinib) while in the retrospective series 4 patients received TKIs (type not specified). No immunotherapy with IO is reported in either Correa et al series. In Singh et al, 9 patients received a TKI (Pazopanib, Sunitinib or Sorafenib) and 1 received bevacizumab. In addition, 6 of these patients also received Nivolumab (Nivo). Details regarding dose and timing of systemic therapy in relation to SBRT and subsequent response is not reported.

\section{Combination SBRT and IO in mRCC}

The studies detailed in Table 2 use various combinations of SBRT with IO. RADVAX (24) and NIVES (25) are ongoing clinical trials with published preliminary results in abstract form. RADVAX RCC is a multi-institution single arm phase II trial assessing the outcomes of combination SBRT to 1-2 metastatic sites with dual IO therapy using Nivo and Ipilimumab (Ipi). The primary outcome is safety and secondary outcome is objective response rate (ORR). NIVES is also a single arm phase II multicenter study with single agent Nivo and SBRT to a single metastasis. The primary outcome is ORR and secondary outcomes are progression free survival (PFS), overall survival (OS) and toxicity. Both RADVAX and NIVES have timed SBRT to be delivered after the first cycle of IO. Dengina et al (26) conducted a single arm prospective study in patients with stable mRCC currently on systemic therapy with either TKIs or IO. Of the 17 patients enrolled, only 5 were treated with IO therapy using Nivo. There was no standardized dose for SBRT delivery to a targeted lesion, with the mean equivalent dose in 2 Gy per fraction (EQD2) being 114 Gy (ranging from 40-276 Gy). A non-irradiated control lesion in the same organ was identified. Primary outcome was safety and secondary outcome was treatment response and time to progression in treated lesion vs. control lesion. Ansari et al (27) retrospectively reviewed 15 patients with either $\mathrm{mRCC}(\mathrm{N}=7)$ or metastatic non-small cell lung cancer (mNSCLC, $\mathrm{N}=8$ ). In total, 32 sites of metastases were treated in the 15 patients with 5 of these sites receiving SBRT and 27 receiving traditional palliative radiation. Patients were on immunotherapy with Nivo and received either palliative doses or SBRT doses of radiation, with 
the most common indication for radiation being oligoprogressive disease (59\% of patients). Outcomes of interest were radiologic response rate in target lesion, toxicity and symptom relief.

Toxicity

Toxicity of combination SBRT and IO is reported in Table 2. In RADVAX, $40 \%$ of patients experienced immune related adverse events (AE) requiring oral prednisone however the specific $\mathrm{AE}$ and breakdown in severity is not detailed. No patients were reported to have discontinued therapy due to AE. In NIVES, $10.1 \%$ of patients discontinued IO therapy due to AE with $24.6 \%$ of patients experiencing grade 3-4 immune related AE (most commonly diarrhea, amylase/lipase increase or hypothyroidism). SBRT toxicity rates are mentioned in NIVES, where it is reported that no grade 3-4 AE with SBRT occurred. Ansari et al report 2 patients who experienced grade 2 pneumonitis and no grade 3-4 AE. Toxicity rates for the mRCC patients in this series was not specified. Dengina et al reported no grade 2 or higher AE seen from SBRT. Grade 1 AE were experienced in 2 patients, with 1 experiencing esophagitis and the other experiencing radiation dermatitis. The authors of all studies conclude that the safety profile of combination SBRT with IO is acceptable.

\section{Response outcomes}

RADVAX reports an ORR of 56\% in non-irradiated lesions, all partial responses (PR). Additional outcomes are yet to be reported with ongoing follow up. NIVES reports a 19\% ORR in non-irradiated lesions with 1 patient experiencing a complete response (CR). Preliminary PFS and OS are reported as 4 months and 22.4 months respectively. Further results from NIVES with ongoing follow up will be reported. Dengina et al report $76 \%$ response in the treated lesion with 1 patient experiencing an abscopal response with SBRT and TKI therapy. Specific outcomes for patients who received Nivo is not detailed however the authors found no differences in response rate between those treated with Nivo vs those treated with TKIs. Ansari et al report a 70\% response rate in the radiated lesion with 3 lesions demonstrating a complete response. In addition, 9 metastatic lesions were treated with radiation due to pain and of these sites responded to radiotherapy.

\section{Discussion}

Cytoreduction in mRCC was originally developed in the interferon (IFN) era $(10,11)$ and supported by retrospective series (12) suggesting a role in the targeted era. It was hypothesized that removal of the primary prevented further seeding of metastatic disease, prevented complications of pain and hemorrhage from the primary tumor, and improved performance status for systemic therapy (11). The role of $\mathrm{CN}$ with contemporary combination IO approaches has come into question. The CARMENA trial demonstrated non-inferior survival with sunitinib alone compared to $\mathrm{CN}$ followed by sunitinib (13) in intermediate/poor risk patients. As yet, prospective evidence supporting the use of $\mathrm{CN}$ with combination IO remains an unmet need. 
Preclinical models suggest that radiation can induce the tumor microenvironment and draining lymph nodes to promote both the primer and effector phases of the anti-tumor immune response (28). Examples include promoting anti-tumor immunity through major histocompatibility complex (MHC) 1 expression (29) and IFN-gamma secretion (30), expression and generation of molecular signals to promote the uptake and presentation of tumor derived antigens by dendritic cells (16) and increasing tumor infiltrating lymphocytes and effector T cells (17). CN may remove these primer and effector processes, thus potentially dampening the immune response. SBRT offers an alternative and less invasive cytoreductive approach in mRCC, particularly for those patients deemed unsuitable for $\mathrm{CN}$, while still maintaining the proimmunogenic advantages. This is supported by the demonstration by Singh et al (21) where increased expression of tumor associated antigens (TAA) and proliferating $\mathrm{CD} 8^{+} \mathrm{T}$ cells after SBRT were found in radiated tumor specimens compared to historical controls. The use of SBRT for cytoreduction is a novel concept in $\mathrm{mRCC}$ and this review demonstrates the limited literature dealing with SBRT to primary kidney in mRCC. All 3 studies demonstrated that SBRT can be safely delivered with acceptable toxicity, even in the scenario of planned surgery. However, the low patient numbers and heterogeneity between studies makes it difficult to draw any significant conclusions despite promising results, particularly as Singh et al did not use SBRT for cytoreductive purposes.

With IO now becoming standard first line care in $\mathrm{mRCC}$ there is growing interest in utilizing these agents with SBRT. The exact mechanism of SBRT immunomodulation in the setting of IO in an active area of research. Thus, a number of prospective clinical trials are currently underway to investigate the combination of IO and SBRT in mRCC. As previously mentioned, there is optimism that SBRT and IO therapy may be the basis to understanding the abscopal response, whereby both targeted and non-targeted sites of disease respond post radiation (18-20). RADVAX and NIVES are still ongoing and have yet to publish long term data of all outcomes. Current results are mostly limited to safety profile and radiologic response rates with short follow up. There is limited survival data reported with only NIVES reporting an OS and PFS rate. Based on preliminary data from these prospective trials, the toxicity profile of combination therapy with IO and SBRT doesn't appear to be worse than toxicity rates reported in major clinical trials establishing dual IO as first line systemic therapy $(29,30)$. Whether the ORR ends up translating to meaningful benefit for patients will have to await longer follow up data. Conclusions from the Dengina et al and Ansari et al series are difficult given the heterogeneous patient populations. Various systemic therapies were used in Dengina et al with a minority receiving Nivo. Various radiation doses were used in both series, and in Ansari et al, majority of lesions received what would be considered more traditional palliative doses rather than true ablative doses. Given this, combination therapy appears to be tolerable and safe for patients however for now, the standard of care remains systemic therapy alone with IO. 
An aspect of combination SBRT and IO therapy that remains unclear is the sequencing and dose fractionation of SBRT. There appears to be differences in optimal timing depending on IO agent (31). Blockade of PD-1 and PD-L1 appears to work best when administered concurrently with radiation due to the effect on newly activated and exhausted T cells (32) while CTLA-4 inhibition works best when administered prior to radiation due to action on naïve and regulatory T cells (33). In addition, pre-clinical models suggest that the largest possible dose per fraction may not be the most immunogenic and that doses ranging from 8-10 Gy per fraction in 1-3 fractions may be sub therapeutic but provide the strongest anti-tumor immune response $(34,35)$. As demonstrated in our search for prospective and retrospective evidence, the timing and dose/fraction is still unclear with variation in how SBRT and IO are being delivered in clinical practice.

To that end, this review points to the dire need of well-conducted, pragmatic trials to address these questions. One trial of particular interest is CYTOSHRINK (NCT04090710), a phase II multi-center randomized controlled trial evaluating upfront cytoreductive SBRT to primary kidney in $\mathrm{mRCC}$ with combination Ipi/Nivo in patients who are deemed $\mathrm{CN}$-ineligible (36). The primary outcome is progression free survival. We eagerly await the results of this trial and others to inform our management of mRCC.

\section{Conclusions}

Cytoreductive SBRT and combination SBRT with IO therapy represent promising treatment strategies in mRCC. The evidence for clinical benefit is currently limited and require further study with well-designed randomized controlled trials to inform our practice. Systemic therapy with dual IO remains standard of care. Ultimately, patients with mRCC would benefit from multi-disciplinary discussion to ensure rational timing and use of systemic therapy, surgery, and/or radiation where appropriate. Our care for these patients would be further enhanced by the availability of nimble, pragmatic clinical trials that reflect the remarkably evolving landscape of this disease. 


\section{References}

1. Coppin C, Porzsolt F, Autenrieth M, et al. Immunotherapy for advanced renal cell cancer. Cochrane Database of Systematic Reviews 2005; 25 (1): CD001425

2. Schwartz R, Stover L, Dutcher J. Managing toxicities of high dose interleukin-2. Oncology 2002; 16:11-20

3. Jonasch E, Haluska FG. Interferon in oncological practice: a review of interferon biology, clinical applications and toxicities. Oncologist 2001; 6:34-55

4. R.J. Motzer, T.E. Hutson, P. Tomczak, et al. Overall survival and updated results for sunitinib compared with interferon alfa in patients with metastatic renal cell carcinoma. $J$ Clin Oncol 2009; 27:3584-90

5. C.N. Sternberg, I.D. Davis, J. Mardiak, et al. Pazopanib in locally advanced or metastatic renal cell carcinoma: results of a randomized phase III trial. J Clin Oncol 2010; 28:106168

6. Motzer RJ, Tannir NM, McDermott DF et al. Nivolumab plus ipilimumab versus sunitinib in advanced renal-cell carcinoma. $N$ Engl J Med. 2018; 378: 1277-90

7. Rini BI, Plimack ER, Stud V et al. Pembrolizumab plus axitinib versus sunitinib for advanced renal-cell carcinoma. N Engl J Med. 2019; 380:1116-27

8. Lalani AA, McGregor BA, Albiges L, et al. Systemic treatment of metastatic clear cell cenal cell carcinoma in 2018: current paradigms, use of immunotherapy, and future directions. Eur Urol 2019; 75:100-10

9. Hotte SJ, Kapoor A, Basappa NS, et al. Management of advanced kidney cancer: Kidney Cancer Research Network of Canada (KCRNC) consensus update 2019. Can Urol Assoc J 2019; 13:343-54

10. Flanigan, RC, Salmon SE, Blumenstein BA, et al. Nephrectomy followed by interferon alfa-2b compared with interferon alfa-2b alone for metastatic renal-cell cancer. $N$ Eng $J$ Med 2001; 345: 1655-59

11. Mickisch G, Garin A, Poppel HV, et al. Radical nephrectomy plus interferon-alfa-based immunotherapy compared with interferon alfa alone in metastatic renal-cell carcinoma: a randomised trial. The Lancet 2001; 358: 966-70

12. Heng DY, Wells JC, Rini Bl et al. Cytoreductive nephrectomy in patients with synchronous metastases from renal cell carcinoma: results from the International Metastatic Renal Cell Carcinoma Database Consortium. Eur Urol 2014; 66: 704-10

13. Méjean A, Ravaud A, Thezenas S et al. Sunitinib Alone or after Nephrectomy in Metastatic Renal-Cell Carcinoma. N Engl J Med 2018; 379:417-27

14. Correa RJM, Louie AV, Zaorsky NG et al. The emerging role of stereotactic ablative radiotherapy for primary renal cell carcinoma: a systematic review and meta analyses. Eur Urol Focus 2019; 5: 958-69

15. Zaorsky NG, Lehrer EJ, Kothari G et al. Stereotactic ablative radiotherapy for oligometastatic renal cell carcinoma (SABR-ORCA): a meta-analysis of 28 studies. Eur Urol Oncol 2019; 2: 515-23

16. Gupta A, Probst H.C, Vuong V, et al. Radiotherapy promotes tumor-specific effector CD8+ T cells via dendritic cell activation. J Immunol 2012; 189: 558-66 
17. Lugade AA, Moran JP, Gerber SA, et al. Local radiation therapy of B16 melanoma tumors increases the generation of tumor antigen-specific effector cells that traffic to the tumor. J Immunol 2005; 174: 7516-23

18. Sharabi AB, Nirschl CJ, Kochel CM, et al. Stereotactic radiation therapy augments antigen-specific PD-1-mediated antitumor immune responses via cross-presentation of tumor antigen. Cancer Immunol Res 2015; 3: 345-55

19. Twyman-Saint Victor C, Rech AJ, Maity A, et al. Radiation and dual checkpoint blockade activate non-redundant immune mechanisms in cancer. Nature 2015; 520: 37377

20. Park SS, Dong H, Liu X et al. PD-1 restrains radiotherapy-induced abscopal effect. Cancer Immunol Res 2015; 3: 610-19

21. Singh AK, Winslow TB, Kermany MH et al. A pilot study of stereotactic body radiation therapy combined with cytoreductive nephrectomy for metastatic renal cell carcinoma. Clin Cancer Res 2017; 23: 5055-65

22. Correa RJM, Ahmad B, Warner A et al. A prospective phase I dose-escalation trial of stereotactic ablative radiotherapy (SABR) as an alternative to cytoreductive nephrectomy for inoperable patients with metastatic renal cell carcinoma. Radiat Oncol 2018; 13: 47

23. Correa RJM, Rodrigues GB, Chen $\mathrm{H}$ et al. Stereotactic ablative radiotherapy (SABR) for large renal tumors: a retrospective case series evaluating clinical outcomes, toxicity and technical considerations. Am J Clin Oncol 2018; 41: 568-75

24. Hammers HJ, Vonmerveldt D, Chul A et al. Combination of dual immune checkpoint inhibition (ICI) with stereotactic radiation (SBRT) in metastatic renal cell carcinoma (mRCC) (RADVAX RCC) [abstract]. J Clin Oncol 2020; 38 suppl 6; abstract 614

25. Masini C, Iotti C, De Giorgi U et al. Nivolumab (NIVO) in combination with stereotactic body radiotherapy (SBRT) in pretreated patients (pts) with metastatic renal cell carcinoma (mRCC): first results of phase II NIVES study [abstract]. J Clin Oncol 2020; 38 suppl 6; abstract 613

26. Dengina N, Mitin T, Gamayunov S et al. Stereotactic body radiation therapy in combination with systemic therapy for metastatic renal cell carcinoma: a prospective multicentre study. ESMO Open 2019; 4: e000535

27. Ansari A, Farrag J, Ali A, et al. Concurrent nivolumab and radiotherapy to improve outcomes for patients with metastatic lung and renal cancers [abstract]. J Clin Oncol 2018; suppl; abstract e15078

28. Buttigliero C, Allis S, Tucci M et al. Role of radiotherapy in improving activity of immune-modulating drugs in advanced renal cancer: biological rationale and clinical evidence. Cancer Treat Rev 2018; 69: 215-23

29. Reits EA, Hodge JW, Herberts CA et al. Radiation modulates the peptide repertoire, enhances MHC class 1 expression and induces successful anti-tumor immunotherapy. $J$ Exp Med 2006; 203: 1259-71

30. Lugade AA, Sorensen EW, Gerber SA et al. Radiation induced IFN-gamma production within the tumor microenvironment influences anti-tumor immunity. J Immunol. 2005; 174: $7516-23$ 
31. Buchwald Z, Wynne J, Nasti TH et al. Radiation, immune checkpoint blockade and the abscopal effect: a critical review on timing, dose and fractionation. Front Oncol. 2018; 8:612

32. Young KH, Baird JR, Savage T et al. Optimizing timing of immunotherapy improves control of tumors by hypofractionated radiation therapy. PLOS ONE. 2016; 11: e 0157164

33. Dovedi SJ, Adlard AL, Lipowska-Bhalla G et al. Acquired resistance to fractionated radiotherapy can be overcome by concurrent PD-L1 blockade. Cancer Res. 2014 74:5458-68

34. Schaue D, Ratikan JA, Iwamoto KS, McBride WH. Maximizing tumor immunity with fractionated radiation. Int J Radiat Oncol Biol Phys. 2012; 83:1306-10

35. Dewan MZ, Galloway AE, Kawashima N, et al. Fractionated but not single-dose radiotherapy induces an immune-mediated abscopal effect when combined with antiCTLA-4 antibody. Clin Cancer Res. 2009; 15:5379-88

36. Lalani AA, Swaminath A, Pond G et al. Phase II trial of cytoreductive stereotactic hypofractionated radiotherapy with combination ipilimumab/nivolumab for metastatic kidney cancer (CYTOSHRINK). J Clin Oncol. 2020; 38 suppl 6; abstract TPS761 


\section{Figures and Tables}

Fig. 1. CONSORT diagram, literature review for SBRT to primary kidney in metastatic renal cell carcinoma. ASCO: American Society of Clinical Oncology; ASTRO: American Society for Radiation Oncology; SBRT: stereotactic body radiotherapy.

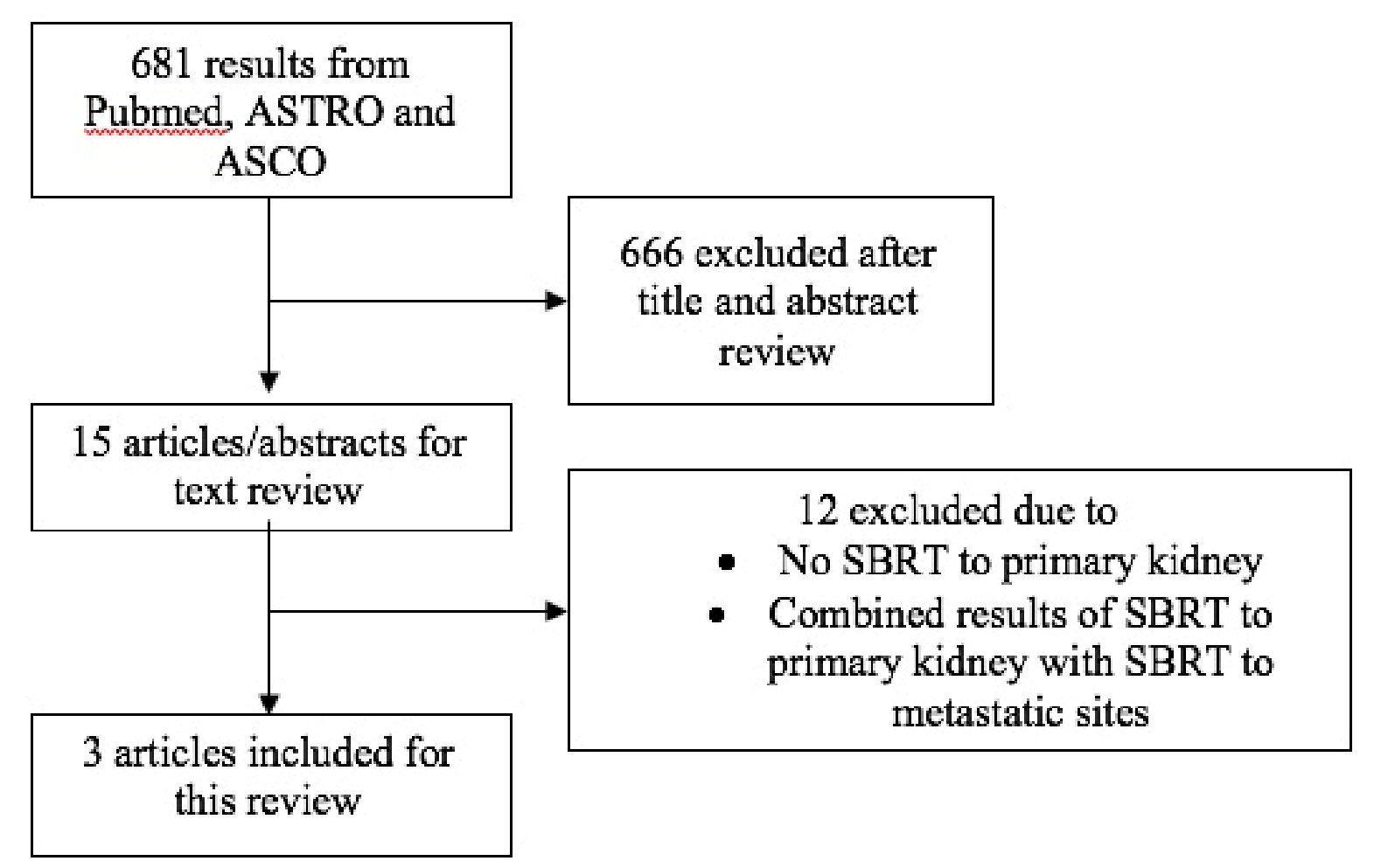


Fig. 2. CONSORT diagram, literature review for SBRT and ICIs in metastatic renal cell carcinoma. ASCO: American Society of Clinical Oncology; ASTRO: American Society for Radiation Oncology; ICI: immune checkpoint inhibitor; SBRT: stereotactic body radiotherapy.

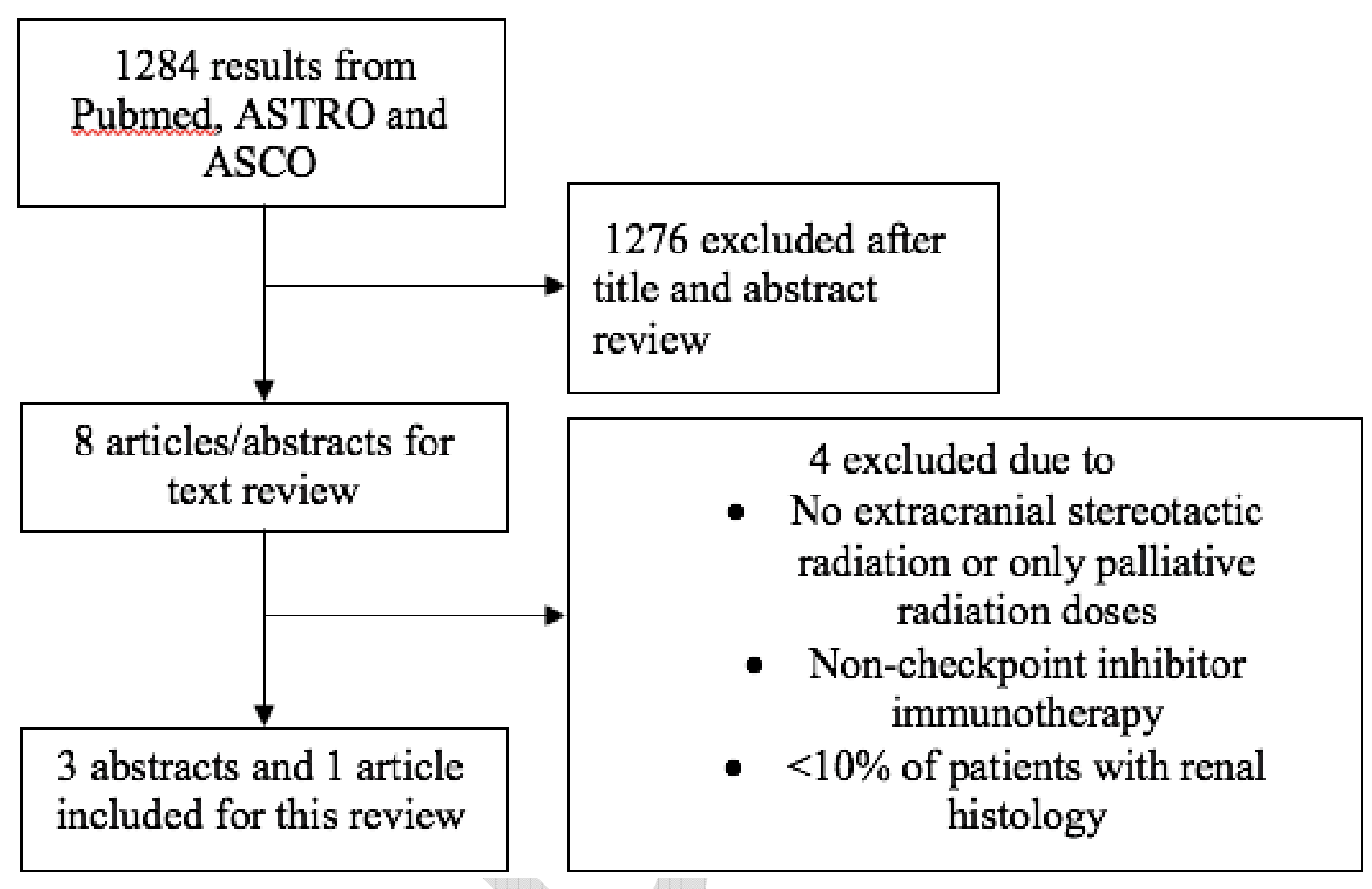




\begin{tabular}{|c|c|c|c|c|c|c|c|c|c|}
\hline Authors & $\begin{array}{c}\text { Number of } \\
\text { patients }\end{array}$ & $\begin{array}{c}\text { Median } \\
\text { age }\end{array}$ & $\begin{array}{c}\text { IMDC } \\
\text { group }(\%)\end{array}$ & Histology & $\begin{array}{l}\text { Median } \\
\text { size, cm }\end{array}$ & $\begin{array}{c}\text { Radiation } \\
\text { dose } \\
\text { (Gy)/fraction }\end{array}$ & $\begin{array}{c}\text { Local } \\
\text { control }\end{array}$ & $\begin{array}{c}\text { Overall } \\
\text { survival }\end{array}$ & $\begin{array}{l}\text { Median } \\
\text { followup } \\
\text { (months) }\end{array}$ \\
\hline $\begin{array}{l}\text { Singh et al, } \\
2017\end{array}$ & $14^{\mathrm{a}}$ & 64 & $\begin{array}{c}\text { Intermediate: } 13 \\
\text { Poor: } 1\end{array}$ & $\begin{array}{c}\text { Clear-cell: } 12 \\
\text { Chromophobe: } 1 \\
\text { Papillary } \\
\text { urothelial: } 1\end{array}$ & $\begin{array}{c}\text { Not } \\
\text { reported }\end{array}$ & $15 / 1$ & $\begin{array}{c}\text { Not } \\
\text { reported }\end{array}$ & $\begin{array}{l}\text { 1-year: } 71 \% \\
\text { 2-year: } 48 \% \\
\text { Median: Not } \\
\text { reported }\end{array}$ & Not reported \\
\hline $\begin{array}{l}\text { Correa et al, } \\
2018- \\
\text { prospective }\end{array}$ & 12 & 67 & $\begin{array}{c}\text { Favorable: } 1 \\
\text { Intermediate: } 8 \\
\text { Poor: } 3\end{array}$ & $\begin{array}{l}\text { Clear-cell: } 9 \\
\text { Papillary: } 2 \\
\text { Poorly } \\
\text { differentiated } \\
\text { carcinoma: } 1\end{array}$ & 8. & $\begin{array}{l}25 / 5: 3 \\
30 / 5: 6 \\
35 / 5: 3\end{array}$ & $100 \%$ & $\begin{array}{l}\text { 1-year: } 38 \% \\
\text { 2-year: } 19 \% \\
\text { Median: } 6.7 \\
\text { months }\end{array}$ & 5.8 \\
\hline $\begin{array}{l}\text { Correa et al, } \\
2018- \\
\text { retrospective }\end{array}$ & $11^{\mathrm{c}}$ & 79 & $\begin{array}{c}\text { Intermediate: } 6 \\
\text { Poor: } 5\end{array}$ & $\begin{array}{c}\text { Clear-cell: } 5 \\
\text { Spindle-cell: } 1 \\
\text { Undifferentiated: } \\
1 \\
\text { Unknown: } 4\end{array}$ & 9.5 & $\begin{array}{l}25 / 5: 6 \\
30 / 5: 3 \\
35 / 5: 1 \\
40 / 5: 1\end{array}$ & $85 \%{ }^{\mathrm{d}}$ & $\begin{array}{c}\text { 1-year: } 53 \% \\
\text { 2-year: } 53 \% \\
\text { Median: } 20.4 \\
\text { months }\end{array}$ & 46.8 \\
\hline
\end{tabular}

${ }^{\mathrm{a}}$ Initially 16 but 2 patients did not go on to receive surgery. ${ }^{\mathrm{b}}$ Only clear-cell histology patients included in statistical analysis. ${ }^{\mathrm{c}}$ Three patients were locally advanced unresectable. ${ }^{\mathrm{d} O n l y} 7$ patients had followup imaging to assess for local control. IMDC: International Metastatic RCC Database Consortium; mRCC: metastatic renal cell carcinoma; SBRT: stereotactic body radiotherapy. 


\begin{tabular}{|c|c|c|c|c|c|c|c|c|}
\hline Authors & $\begin{array}{c}\text { Number } \\
\text { of } \\
\text { patients }\end{array}$ & $\begin{array}{c}\text { Median } \\
\text { age }\end{array}$ & $\begin{array}{l}\text { IMDC } \\
\text { group }\end{array}$ & Histology & Immunotherapy & $\begin{array}{c}\text { Radiation } \\
\text { dose } \\
\text { (Gy)/fraction }\end{array}$ & Toxicity & Outcomes \\
\hline $\begin{array}{l}\text { Hammers et } \\
\text { al, } 2020 \\
\text { RADVAX } \\
\text { RCC - } \\
\text { abstract }\end{array}$ & 25 & $\begin{array}{c}\text { Not } \\
\text { reported }\end{array}$ & $\begin{array}{c}\text { Favorable: } 2 \\
\text { Intermediate: } 20 \\
\text { Poor: } 3\end{array}$ & Clea & $\begin{array}{c}\text { Nivolumab } \\
\text { (Nivo) }(3 \mathrm{mg} / \mathrm{kg}) \\
\text { and ipilimumab } \\
\text { (Ipi) }(1 \mathrm{mg} / \mathrm{kg}) \\
\text { IV q3weeks } \\
\text { followed by } \\
\text { Nivo } \\
\text { monotherapy }\end{array}$ & $\begin{array}{c}50 / 5 \\
\text { delivered to } \\
1-2 \\
\text { metastatic } \\
\text { lesions } \\
\text { between the } \\
1^{\text {st }} \text { and } 2^{\text {nd }} \\
\text { cycle of } \\
\text { Nivo/Ipi }\end{array}$ & $\begin{array}{l}40 \% \text { patients } \\
\text { required oral } \\
\text { prednisone } \\
\text { for classic } \\
\text { immune- } \\
\text { related AEs } \\
8 \% \text { grade } 2 \\
\text { pneumonitis }\end{array}$ & $\begin{array}{l}56 \% \text { ORR of } \\
\text { non- } \\
\text { irradiated } \\
\text { lesions, all } \\
\text { PR }\end{array}$ \\
\hline $\begin{array}{l}\text { Masini et al, } \\
2020 \\
\text { NIVES - } \\
\text { abstract }\end{array}$ & 69 & 67 & $\begin{array}{c}\text { Favorable: } 14 \\
\text { Intermediate/Poor: } \\
55\end{array}$ & $\begin{array}{c}\text { Clear-cell: } 55 \\
\text { Other not } \\
\text { specified: } 14\end{array}$ & $\begin{array}{l}\text { Nivo } 240 \mathrm{mg} \text { IV } \\
\text { Day } 1 \text { q2weeks x } \\
6 \text { months then } \\
480 \mathrm{mg} \text { IV } \\
\text { q4weeks in } \\
\text { responding } \\
\text { patients until } \\
\text { progression or } \\
\text { unacceptable } \\
\text { toxicity }\end{array}$ & $\begin{array}{c}30 / 3 \\
\text { delivered to } 1 \\
\text { metastatic } \\
\text { lesion } 7 \text { days } \\
\text { after } 1^{\text {st }} \text { Nivo }\end{array}$ & $\begin{array}{c}10 \% \\
\text { discontinued } \\
\text { treatment } \\
\text { due to AE } \\
25 \% \\
\text { experienced } \\
\text { grade 3-4 } \\
\text { immune- } \\
\text { related } \\
\text { toxicity }\end{array}$ & $\begin{array}{l}\text { 19\% ORR of } \\
\text { non-irradiated } \\
\text { lesions, } 1 \\
\text { patient had } \\
\text { CR } \\
\text { Median PFS } 4 \\
\text { months, } \\
\text { median OS } \\
22.4 \text { months }\end{array}$ \\
\hline
\end{tabular}




\begin{tabular}{|c|c|c|c|c|c|c|c|c|}
\hline & & & & & & & $\begin{array}{l}\text { No grade 3- } \\
4 \text { toxicities } \\
\text { from SBRT }\end{array}$ & \\
\hline $\begin{array}{l}\text { Dengina et al, } \\
2019\end{array}$ & 17 & 54.5 & Not reported & Clear-cell: 17 & $\begin{array}{l}\text { Nivo }(\mathrm{n}=5) \text {, dose } \\
\text { and scheduling } \\
\text { not specified }^{\mathrm{a}}\end{array}$ & $\begin{array}{c}\text { Various } \\
\text { doses not } \\
\text { specified, }{ }^{b} \\
\text { delivered } \\
\text { same day as } \\
\text { systemic } \\
\text { therapy } \\
(\mathrm{n}=15) \text { or in } \\
\text { between } \\
\text { cycles }(\mathrm{n}=2)\end{array}$ & $\begin{array}{c}\text { Grade } 1 \\
\text { toxicity } 12 \% \\
\text { No grade } 2 \\
\text { or higher } \\
\text { toxicity seen }\end{array}$ & $\begin{array}{c}76 \% \text { response } \\
\text { rate in target } \\
\text { lesion, } 5 \\
\text { patients had } \\
\text { CR and } 8 \text { had } \\
\text { PR }\end{array}$ \\
\hline $\begin{array}{l}\text { Ansari et al, } \\
2018- \\
\text { abstract }\end{array}$ & $15^{\mathrm{c}}$ & 59 & Not reported & Not reported & $\begin{array}{l}\text { Nivo, dose and } \\
\text { schedule not } \\
\text { specified }\end{array}$ & $\begin{array}{c}\text { Various } \\
\text { doses not } \\
\text { specified, }{ }^{\mathrm{d}} \\
\text { delivered to a } \\
\text { total of } 32 \\
\text { lesions within } \\
2 \text { weeks of } \\
\text { Nivo }\end{array}$ & $\begin{array}{l}\text { No grade 3- } \\
4 \mathrm{AE}, 2 \\
\text { patients had } \\
\text { grade } 2 \\
\text { pneumonitis }\end{array}$ & $\begin{array}{c}70 \% \text { response } \\
\text { rate in target } \\
\text { lesion with } 3 \\
\text { lesions } \\
\text { demonstrating } \\
\text { CR }\end{array}$ \\
\hline
\end{tabular}


${ }^{a}$ Others treated with sunitinib $(n=6)$, everolimus $(n=3)$, lenvatinib + everolimus $(n=1)$, temsirolimus $(n=1)$, and sorafenib $(n=1)$. ${ }^{b} M e a n$ equivalent dose in 2 Gy (EQD2) 114 Gy (range 40-276). ${ }^{\mathrm{N}} \mathrm{N}=7$ with $\mathrm{mRCC}$, other 8 patients had metastatic non-small-cell lung cancer. dboth SBRT and traditional palliative doses given. AE: adverse event; CR: complete response; IMDC: International Metastatic RCC Database Consortium; mRCC: metastatic renal cell carcinoma; ORR: objective response rate; OS: overall survival; PFS: progression-free survival; PR: partial response; SBRT: stereotactic body radiotherapy. 